\title{
A Review of the Importance of Atypical Otorhinolaryngological Symptoms in the Screening of COVID-19 Patients
}

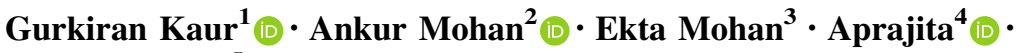 \\ Mamta Mohan ${ }^{5}$ (D)
}

Received: 10 April 2020/Accepted: 8 August 2020/Published online: 17 August 2020

(C) Association of Otolaryngologists of India 2020

\begin{abstract}
While the world is fighting against the newly emerged highly contagious coronavirus strain, new evolving ideas regarding symptoms and investigations are reverberating among health care professionals to combat the public health emergency. The study aims to review various presenting symptoms of COVID-19 especially the unusual one and analyzing the importance of olfactory and taste disturbances. 20 studies published recently in the last 1 year were analyzed and discussed for insights into the unusual presentation of symptoms in COVID-19 patients. All the findings and statements in this review regarding the pandemic are based on published information as listed in
\end{abstract}

Ankur Mohan

doctorocks@gmail.com

Gurkiran Kaur

gurkiranmarwah23@gmail.com

Ekta Mohan

ektamohan@rocketmail.com

Aprajita

dr_aprajita_04@yahoo.com

Mamta Mohan

mamtamohan16@yahoo.in

1 Department of Otorhinolaryngology, Head and Neck Surgery, Government Medical College, Patiala, Punjab, India

2 Department of Otorhinolaryngology, Head and Neck Surgery, Kalra Multi Speciality Hospital, Ludhiana, Punjab, India

3 Department of Anaesthesia, All India Institute of Medical Sciences, Bhatinda, Punjab, India

4 Department of Physiology, Government Institute of Medical Sciences, Greater Noida, UP, India

5 Department of Physiology, All India Institute of Medical Sciences, Bhatinda, Punjab, India the references. Most research articles initially focused on fever and respiratory symptoms. Later gastrointestinal symptoms were also taken into consideration. Only 5 studies from the literature have mentioned any smell and taste disturbances after SARS-CoV-2 infection to date. So changing trends can be seen in publications and recognizing these symptoms has important to timely combat this disease. The majority of corona virus-infected patients suffer from mild to moderate severity of the disease. Much hyped up symptoms of the respiratory tract may not be shown by a greater number of patients. So the need of the hour especially in developing and densely populated nations is to recognize unusual symptoms of COVID-19 especially its influence over smell and taste sensation to prevent any delay or misdiagnosis.

Keywords COVID 19 - Olfactory and taste disturbances . Symptoms $\cdot$ Coronavirus

\section{Introduction}

The epicentre of coronavirus is well known to be the seafood market of Wuhan, China when a sudden rise of atypical and fatal cases of pneumonia occurred in the province in Dec 2019. On Jan 7, a novel coronavirus was identified by the Chinese Center for Disease Control and Prevention (CDC) from the throat swab sample of a patient and was subsequently named $2019 \mathrm{nCoV}$ by WHO [1] When the genomics of the 2019-novel was sequenced, it shared $79.5 \%$ of the genetic sequence of the SARS-CoV that caused the 2002-2003 pandemic [2] and the International Committee on Taxonomy of Viruses renamed the 2019-nCov as SARS-CoV-2 [3]. The COVID-19 has been found to have higher levels of transmissibility and 
pandemic risk as the effective reproductive number $\left(\mathrm{R}_{0}\right)$ of COVID-19 (2.9) is estimated to be higher [4]. It was likely transmitted to humans through pangolins that are illegally sold in Chinese markets $[5,6]$.

The common clinical manifestations which give suspicion and further forms criteria for testing of coronavirus infection include fever $(98 \%)$, cough $(76 \%)$, shortness of breath $(55 \%)$, muscle ache $(44 \%)$ and rare symptoms includes confusion, headache, sore throat, rhinorrhea, chest pain, diarrhea, nausea, and vomiting [1]. WHO has issued case definitions for the suspect, probable and confirmed cases. But no importance is given to atypical otolaryngological manifestation of viral diseases such as hyposmia, anosmia, parosmia, and dysgeusia.

Pathophysiology suggests that viruses can invade the central nervous system through the olfactory neuro-epithelium and olfactory pathways [7]. Damage may occur at the level of the epithelium and receptor cells, or in central processing pathways such as the olfactory bulb [8]. Like other respiratory viruses, SARS-COV-2 may enter the CNS through the hematogenous or retrograde neuronal route [9]. So olfactory dysfunction in the early stages of the disease, in asymptomatic carriers or one with mild to moderate disease, cannot be ignored. Although there is no evidence of direct involvement of taste buds but the retronasal airflow occurs during swallowing. This retronasal route is vital to the production of flavor from swallowed foodsadding smell to both taste and touch [10].

The study aims to review various presenting symptoms of COVID-19 especially the atypical one and analyzing the importance of olfactory and taste disturbances.

\section{Methods}

The review study was done and the following steps were followed:

1. Identification of research articles based on clinical features and diagnosis,

2. Selection of relevant articles,

3. Data extraction and analysis based on atypical features documentation.

\section{Search Methods for Identification of Studies}

Electronic searches or online database used was-Pubmed (Medline), google scholar, medRxiv, BioRxiv and also in "JAMA", "BMJ", "Oxford" and "THE LANCET" journals, WHO guidelines, ENTUK guidelines, AAO-HNS guidelines on coronavirus till date. The search terms used were like nCoV19/olfaction, coronavirus/olfaction, COVID-19, olfaction/ virology, nCoV (2019 novel coronavirus)/olfaction, coronavirus/anosmia, coronavirus/clinical features. We searched relevant literature published to date regarding coronavirus and included all the significant scientific publications written in English in the review. News articles, reports, and Non-scientific commentary were excluded from the analysis.

\section{Identification and Selection of Relevant Studies}

Studies across the globe-clinical case study, review and systematic reviews analyzing the various clinical presentations of COVID-19 in human species (adults) published in the last 1 year (as from 10/4/2020) were identified and studied. Research over olfactory and taste dysfunction was done on priority and old literature was also searched to identify the studies considering these atypical features. 62 unique academic studies were identified after discussion among reviewers. Filtering of articles based on abstract and title was done and duplicates were removed. Only articles published in English were selected for this review.

\section{Data Retrieved from Eligible Articles Analyzed}

Clinical manifestations from each study were analyzed to see the changing trends or any new feature emergence. Only 5 studies from the literature have mentioned any smell and taste disturbances after SARS-CoV-2 infection till date $[9,11]$.

\section{Results and Discussion}

Among the 20 research articles included in the analysis, fever was found to be a dominant symptom in most of the articles [9, 11-29] (Fig. 1) as main stress was given on flulike symptoms except for one study in which fever onset was absent and gastrointestinal symptoms were the initial presentation in coronavirus infected pneumonia patients [26]. These types of unusual presentations can spread the infection not only among the general population but also to healthcare workers sitting in outpatient or screening triage areas without proper protective equipment. But as gastrointestinal symptoms are at least included in diagnostic criteria of SARS-CoV-2 patients but symptoms like olfactory and taste dysfunction are neither assessed nor reported widely can go unnoticed and be a source of regret in near future.

Association of olfactory disturbance and viruses is an old concept. Post viral olfactory dysfunction (PVOD) is a common feature with the observed incidence of $18-45 \%$ [30]. Moreover, anosmia has been reported specifically in the course of severe acute respiratory syndrome (SARS) [31] and other coronaviruses [32] infections but it still 
Fig. 1 Distribution of various presenting symptoms of COVID-19 in reviewed articles. Other features (sore throat, nasal congestion, facial pain, rhinorrhea)

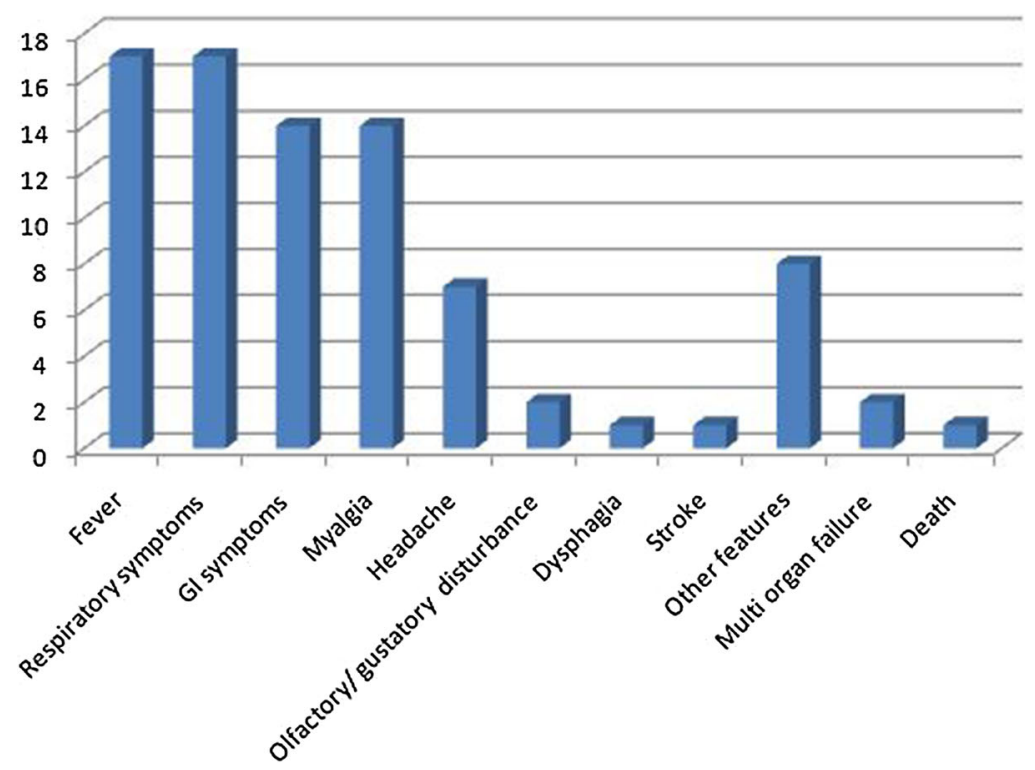

No. of studies

were the most disease-related otolaryngological symptoms. $85.6 \%$ and $88.0 \%$ of patients reported olfactory and gustatory dysfunctions respectively. There was a significant association between both disorders $(p<0.001)$. Among them, $79.6 \%$ of patients were anosmic and $20.4 \%$ were hyposmic. Phantosmia and parosmia were concerned with $12.6 \%$ and $32.4 \%$ of patients during the disease course, respectively. Even it was found that olfactory dysfunction (OD) appeared before the other symptoms in $11.8 \%$ of cases. The olfactory and gustatory disorders were constant and unchanged over the days in $72.8 \%$ of patients [11].

A study by Mao et al. [9] found the neurological manifestations of coronavirus supported by presence ACE-2 receptors in the nervous system manifested hyposmia in $5.1 \%$ and hypogeusia in $5.6 \%$ population demonstrating injury to the peripheral nervous system. Another study that captured the data from 320 patients of Italy estimated that chemosensory dysfunction is present in $19.4 \%$. Although research admits its shortcomings of not always investigating the olfactory and gustatory dysfunction in this emergency situation [27].

While Gane et al. have given a new direction to this dysosmias in COVID-19 infection by publishing a case report and labeling isolated sudden onset anosmia (ISOA) as the fourth important presenting syndrome and urged the international community to consider this manifestation in current management advice [28].

A hypothesis by Keyhan et al. suggests that dysosmia and dysgeusia can be attributed to olfactory nerve and trigeminal nerve damage caused by 2019-nCoV infection or excessive exposure to chemicals and disinfectants that are most commonly used by people due to viral epidemic [29]. 
Multiple anecdotal reports, both from SARS-CoV-2infected patients and medical staff, suggest an association between viral infection and alterations of olfactory perception, ranging from mild perturbations to complete, although reversible anosmia [35]. Recently many doctors from China, Italy, Iran, Germany, France, and even British otolaryngological society also claim olfactory disturbances as new emerging symptoms of COVID-19. The explanation could be based on either mutation of virus strain itself [39] or earlier taste and smell sensation was not assessed and given any importance as most of the data collection was from indoor patients and not much importance is given to the unaware sensation of olfaction. People who are asymptomatic or with olfactory or taste dysfunction as the only symptom may be unknowingly spreading the virus in the community and never report to the hospital with any illness.

It is a known fact that if the power of odor is affected even then its difficult to recognize as concluded by a research paper that states the reduced applicability of selective attention combined with a theorized inhibitory mechanism and additional factors that jointly limit the place of odors in awareness [40]. So here comes the role of an objective test for olfaction like UPSIT, 12-odorant Sniffin-sticks or if smell in the standard olfactory test is unfamiliar then some indigenous method of familiar odors can be used such as 10-odourant Indian Smell Identification Test (INSIT) in India [41].

High resolution computed tomography (HRCT) chest is claimed to be a very sensitive test to evaluate pulmonary changes in coronavirus patients and CT images were reported to show the greatest severity approximately 10 days after the initial onset of symptoms [42]. If a diagnostic test can be given importance in COVID-19 patients without any symptoms of pneumonia, the mere inclusion of new-onset olfactory and taste disturbances in case definition criteria will not do any harm. New-onset dysosmia and dysgeusia in this epidemic season could serve as a warning sign and can make general public cautious of probable case and norms of self-quarantine can be followed.

Therefore, it is important to inform our ENT colleagues about paying attention as anosmia and dysgeusia can be the sole presenting feature that is manifested early in the course of the disease. Although these patients have a milder form of the disease, but they are potential carriers and can add to the burden of disease transmission. So we suggest that these symptoms should be considered highly susceptible to COVID-19 and should be included during the screening of patients.

\section{Conclusion}

In a developing country like India where many people attend pilgrimages in large number and some ignorant people hide travel history and do not disclose their contact with suspected or confirmed coronavirus patients, such atypical otolaryngological presentations of the disease should be recognized at the earliest. Silent carriers are to be captured and unknown vectors need to be reduced to break the chain of virus transmission and prevent community spread of this infection.

Acknowledgements The authors would like to thank all the Indian health workers for the effort and all the sacrifices they are making during this serious health crisis.

Funding Not applicable.

\section{Compliance with Ethical Standards}

Conflict of interest The authors declare that they have no conflict of interest.

\section{References}

1. Chen N, Zhou M, Dong X, Qu J, Gong F, Han Y et al (2020) Epidemiological and clinical characteristics of 99 cases of 2019 novel coronavirus pneumonia in Wuhan, China: a descriptive study. Lancet 395:507-513

2. Zhou P, Yang XL, Wang XG, Hu B, Zhang L, Zhang W et al (2020) A pneumonia outbreak associated with a new coronavirus of probable bat origin. Nature 579:270-273

3. Gorbalenya AE, Baker SC, Baric RS, de Groot RJ, Drosten C, Gulyaeva AA et al (2020) Severe acute respiratory syndromerelated coronavirus: the species and its viruses-a statement of the Coronavirus Study Group. Microbiology. https://doi.org/10.1101/2020.02.07.937862

4. Liu T, Hu J, Kang M, Lin L, Zhong H, Xiao J et al (2020). Transmission dynamics of 2019 novel coronavirus (2019-nCoV). https://doi.org/10.1101/2020.01.25.919787

5. Fan Y, Zhao K, Shi Z-L, Zhou P (2019) Bat coronaviruses in China. Viruses $11: \mathrm{e} 210$

6. Cyranoski D. (2020) Did pangolins spread the China coronavirus to people? https://www.nature.com/articles/d41586-020-00364-2 Accessed 10 Apr 2020

7. Stroop MG (1995) Viruses and the olfactory system. In: Doty RL (ed) Handbook of olfaction and gestation, 2nd edn. Marcel Dekker, New York, pp 367-394

8. Duncan HJ (1997) Postviral olfactory loss. In: Seiden AM (ed) Taste and smell disorders. Thieme, New York, pp 72-78

9. Mao L, Wang M, Chen S et al (2020). Neurological Manifestations of Hospitalized Patients with COVID-19 in Wuhan, China: a retrospective case series study. https://doi.org/10.1101/2020.02.22.20026500

10. Blankenship ML, Grigorova M, Katz DB, Maier JX (2019) Retronasal odor perception requires taste cortex, but orthonasal does not. Curr Biol 29(1):62-69

11. Lechien JR, Chiesa-Estomba CM, De Siati DR et al (2020) Olfactory and gustatory dysfunctions as a clinical presentation of mild-to-moderate forms of the coronavirus disease (COVID-19): 
a multicenter European study. Eur Arch Otorhinolaryngol. https://doi.org/10.1007/s00405-020-05965-1

12. Adhikari SP, Meng S, Wu YJ et al (2020) Epidemiology, causes, clinical manifestation and diagnosis, prevention and control of coronavirus disease (COVID-19) during the early outbreak period: a scoping review. Infect Dis Poverty. https://doi.org/10.1186/s420249-020-00646-x

13. Lake MA (2020) What we know so far: COVID-19 current clinical knowledge and research. Clin Med (Lond) 20(2):124-127

14. Kim JY, Choe PG, Oh Y et al (2020) The first case of 2019 novel coronavirus pneumonia imported into Korea from Wuhan, China: implication for infection prevention and control measures. J Korean Med Sci 35(5):e61

15. Xu J, Zhao S, Teng T, Abdalla AE et al (2020) Systematic comparison of two animal-to-human transmitted human coronaviruses: SARS-CoV-2 and SARS-CoV. Viruses 12(2):e244

16. Xu X, Yu C, Qu J, Zhang L, Jiang S, Huang D (2020) Imaging and clinical features of patients with 2019 novel coronavirus SARS-CoV-2. Eur J Nucl Med Mol Imaging 47(5):1275-1280

17. Li T (2020) Diagnosis and clinical management of severe acute respiratory syndrome Coronavirus 2 (SARS-CoV-2) infection: an operational recommendation of Peking Union Medical College Hospital. Emerg Microbes Infect 9(1):582-585

18. Lo IL, Lio CF, Cheong HH (2020) Evaluation of SARS-CoV-2 RNA shedding in clinical specimens and clinical characteristics of 10 patients with COVID-19 in Macau. Int J Biol Sci 16(10):1698-1707

19. Huang C, Wang Y, Li X et al (2020) Clinical features of patients infected with 2019 novel coronavirus in Wuhan, China. Lancet 395(10223):497-506

20. Mo P, Xing Y, Xcyiao Y (2020) Clinical characteristics of refractory COVID-19 pneumonia in Wuhan, China. Clin Infect Dis. https://doi.org/10.1093/cid/ciaa270

21. Guo Y, Cao Q, Hong Z et al (2020) The origin, transmission and clinical therapies on coronavirus disease 2019 (COVID-19) outbreak-an update on the status. Mil Med Res. https://doi.org/10.1186/s40779-020-00240-0

22. Han R, Huang Lu, Jiang H (2020) Early clinical and CT manifestations of coronavirus disease 2019 (COVID-19) pneumonia. Am J Roentgenol. https://doi.org/10.2214/AJR.20.22961

23. Kim ES, Chin BS, Kang CK, Kim NJ, Kang YM, Choi JP et al (2020) Clinical course and outcomes of patients with severe acute respiratory syndrome coronavirus 2 infection: a preliminary report of the first 28 patients from the Korean Cohort Study on COVID-19. J Korean Med Sci 35(13):e142

24. Fu H, Li H, Tang X et al. Analysis on the clinical characteristics of 36 cases of novel coronavirus pneumonia in Kunming. https://doi.org/10.1101/2020.02.28.20029173

25. Giwa A, Desai A (2020) Novel coronavirus COVID-19: an overview for emergency clinicians. Emerg Med Pract 22(2):1-21

26. An P, Chen H, Jiang X, Su J, Xiao Y, Ding Y, Ren H et al (2020). Clinical features of 2019 novel coronavirus pneumonia presented gastrointestinal symptoms but without fever onset. https://doi.org/10.2139/ssrn.3532530

27. Vaira LA, Salzano G, Deiana G, Riu G (2020) Anosmia and ageusia: common findings in COVID-19 patients.
Otolaryngological manifestations in COVID-19. Laryngoscope. https://doi.org/10.1002/lary.28692

28. Gane SB, Kelly C, Hopkins C (2020) Isolated sudden onset anosmia in COVID-19 infection. A novel syndrome? Rhinology. https://doi.org/10.4193/Rhin20.114

29. Keyhan SO, Fallahi HR, Cheshmi B (2020) Dyosmia and dysgeusia due to 2019 Novel Coronavirus; a hypothesis that needs further investigation. Maxillofac Plast Reconstr Surg. https://doi.org/10.1186/s40902-020-00254-7

30. Nordin S, Brämerson A (2008) Complaints of olfactory disorders: epidemiology, assessment, and clinical implications. Curr Opin Allergy Clin Immunol 8(1):10-15

31. Hwang CS (2006) Olfactory neuropathy in severe acute respiratory syndrome: report of a case. Acta Neurol Taiwan 15(1):26-28

32. De Haro-Licer J, Roura-Moreno J, Vizitiu A, Gonzàlez-Fernàndez A, Gonzàlez-Ares JA (2013) Long term serious olfactory loss in cold and/or flu. Acta Otorrinolaringol Esp 64(5):331-338

33. Zhou P, Yan X L, Wang X G, Hu B, Zhang L, Zhang W et al (2020) Discovery of a novel coronavirus associated with the recent pneumonia outbreak in humans and its potential bat origin. https://doi.org/10.1101/2020.01.22.914952

34. Hamming I, Timens W, Bulthuis MLC, Lely AT, Navis G, Van Goor H (2004) Tissue distribution of ACE2 protein the functional receptor for SARS coronavirus. The first step in understanding SARS pathogenesis. J Pathol 203:631-637

35. Fodoulian L, Tuberosa J, Rossier D, Landis BN, Carleton A, Rodriguez I (2020) SARS-CoV-2 receptor and entry genes are expressed by sustentacular cells in the human olfactory neuroepithelium. https://doi.org/10.1101/2020.03.31.013268

36. Yamagishi M, Fujiwara M, Nakamura H (1994) Olfactory mucosal findings and clinical course in patients with olfactory disorders following upper respiratory viral infection. Rhinology 32(3):113-118

37. Akerlund A, Bende M, Murphy C (1995) Olfactory threshold and nasal mucosal changes in experimentally induced common cold. Acta Otolaryngol 115(1):88-92

38. Suzuki M, Saito K, Min WP et al (2007) Identification of viruses in patients with postviral olfactory dysfunction. Laryngoscope 117(2):272-277

39. Benvenuto D, Giovanetti M, Ciccozzi A, Spoto S, Angeletti S, Ciccozzi M (2020) The 2019-new coronavirus epidemic: evidence for virus evolution. J Med Virol 92(4):455-459

40. Sela L, Sobel N (2010) Human olfaction: a constant state of change-blindness. Exp Brain Res 205(1):13-29

41. George J, Jose T, Behari M (2013) Use of Indian smell identification test for evaluating olfaction in idiopathic Parkinson's disease patients in India. Neurol India 61(4):365-370

42. Pan F, Ye T, Sun P, Gui S, Liang B, Li L et al (2020) Time course of lung changes on chest CT during recovery from 2019 novel coronavirus (COVID-19) pneumonia. Radiology. https://doi.org/10.1148/radiol.2020200370

Publisher's Note Springer Nature remains neutral with regard to jurisdictional claims in published maps and institutional affiliations. 